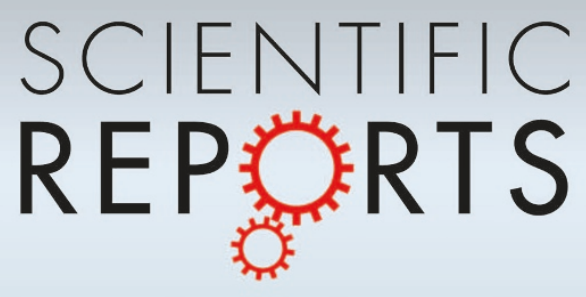

OPEN

SUBJECT AREAS:

PALAEOECOLOGY

PALAEOCLIMATE

CLIMATE-CHANGE ECOLOGY

BIOGEOCHEMISTRY

Received

21 June 2013

Accepted

5 August 2013

Published

22 August 2013

Correspondence and requests for materials should be addressed to L.-G.S. (slg@ustc.edu. cn) or Z.-Q.X. (zqxie@ ustc.edu.cn)

* These authors contributed equally to this work.

\section{Increase in penguin populations during the Little lce Age in the Ross Sea, Antarctica}

\author{
Qi-Hou Hu'*, Li-Guang Sun ${ }^{*}$, Zhou-Qing Xie ${ }^{1 *}$, Steven D. Emslie² \& Xiao-Dong Liu'
}

'Institute of Polar Environment, School of Earth and Space Sciences, University of Science and Technology of China, Hefei 230026, China, ${ }^{2}$ Department of Biology and Marine Biology, University of North Carolina Wilmington, 601 S. College Road, Wilmington, NC 28403, USA.

Penguins are an important seabird species in Antarctica and are sensitive to climate and environmental changes. Previous studies indicated that penguin populations increased when the climate became warmer and decreased when it became colder in the maritime Antarctic. Here we determined organic markers in a sediment profile collected at Cape Bird, Ross Island, high Antarctic, and reconstructed the history of Adélie penguin colonies at this location over the past 700 years. The region transformed from a seal to a penguin habitat when the Little Ice Age (LIA; 1500-1800 AD) began. Penguins then became the dominant species. Penguin populations were the highest during ca. 1490 to $1670 \mathrm{AD}$, a cold period, which is contrary to previous results in other regions much farther north. Different responses to climate change may occur at low latitudes and high latitudes in the Antarctic, even if for same species.

enguin colonies are high-density breeding sites that also support plants such as algae, mosses and lichens ${ }^{1}$. They thus form a simple and important terrestrial ecosystem in Antarctica. Using bioelements and organic markers in the sediments from an accumulation of penguin guano, it has been possible to reconstruct historical changes of penguin populations and plant communities, and their responses to environmental and climatic changes at many sites around Antarctica ${ }^{1-8}$. Nevertheless, these studies were all conducted north of $70^{\circ} \mathrm{S}$. The Ross Sea region is a higher latitude embayment and contains a disproportionate number of Adélie penguins (Pygoscelis adeliae), which occur only in the Antarctic, and considerable information exists on the occupation history of this species in this region ${ }^{9-14}$. However, continuous records of penguin populations and associated plant communities over the last millennium would provide a better understanding of the evolution of ecosystems under changing climate ${ }^{15,16}$. Herein, we describe findings from a sediment profile (MB6) collected at an active Adélie penguin colony along the northwest beach of Cape Bird, Ross Island in this region ( $166^{\circ} 26^{\prime} 44.4^{\prime \prime} \mathrm{E}, 77^{\circ} 12^{\prime} 47.5^{\prime \prime} \mathrm{S}$; Figure 1 and 2). This profile could represent at least a spatial range of $5 \mathrm{~km}$ (see Methods). By analyzing organic molecular markers in the profile, we were able to reconstruct the penguin and vegetation records over the past 700 years to better understand the relationship between penguins and climate change in the high latitude Ross Sea region.

\title{
Results
}

Sterols from droppings of animals can be used to indicate fecal contamination. In previous studies, cholesterol and cholestanol were used as indicators for historical penguins, and phytol was used as the indicator for total vegetation $^{1,2}$. The sum of cholesterol and cholestanol is significantly correlated with traditional proxies such as total organic carbon (TOC), total nitrogen $(\mathrm{TN})$, and phosphorus $(\mathrm{P})^{17}$ (Figure $3 \mathrm{~b}-\mathrm{d}$ ), and was used as the indicator for penguin populations in this study. Compared to traditional indices, these organic molecular markers are better at distinguishing the influence between vegetative growth and animal activities. It is notable that the TOC, $\mathrm{N}$, and $\mathrm{P}$ concentrations increased prior to the increase of sterols and phytol. This result might be related to the transformation of this location from a seal to a penguin habitat at $\sim 1490 \mathrm{AD}$ (see below). The two species probably had different influences on the input of sterols TOC, $\mathrm{N}$ and $\mathrm{P}$ as well as plant growth. n-Alkanols with even numbers of carbon atoms were also discovered in the sediments (Figure S1), with different arrays of carbon atoms originating from different sources. Around the sampling site, algae and lichens currently are the main species of vegetation. $\mathrm{C}_{18}$-ol and $\mathrm{C}_{28}$-ol were chosen as indicators for algae and lichens, respectively ${ }^{1,2}$. In addition, $\mathrm{n}$-alkanoic acids and n-Alkanes as well as pristane and phytane were simultaneously detected (Figures S2 and S3). 


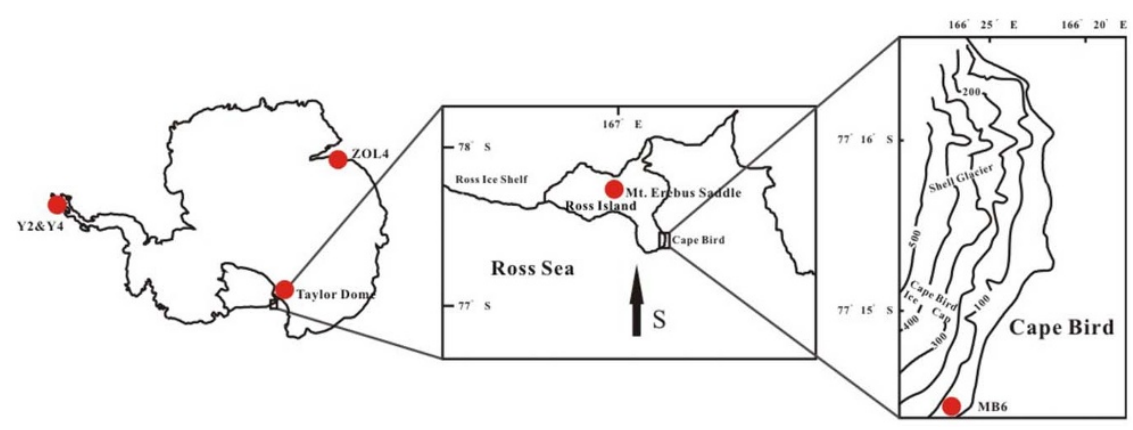

Figure $1 \mid$ Maps of our sampling site on Cape Bird, Ross Island, as well as sampling sites of sediment cores $\mathrm{Y}^{3}$, $\mathrm{Y}^{6}{ }^{6}$ and $\mathrm{ZOL}^{8}$ for penguins and ice cores from Taylor Dome ${ }^{25}$ and Mt. Erebus Saddle ${ }^{19}$. These maps were created using CorelDRAW software.

Because they are not well correlated with penguin population changes, we discuss them in the supplementary information.

Historical record of penguins, seals and vegetation in the past 700 years. The history of the Adélie penguin population and vegetation abundance at Cape Bird during the past 700 years was reconstructed using molecular markers (Figure 3). According to the variation of these markers, the past 700 years were divided into four periods: Period I: 1280-1490 AD; Period II: 1490-1670 AD; Period III: 1670-1950 AD; Period IV: 1950 AD-present.

Cholesterol and cholestanol were detected at the bottom of this profile, indicating the sampling site had been contaminated by animal feces since ca. 1280 AD. The sum of cholesterol and cholestanol increased slowly during this period. However, cholesterol and cholestanol cannot distinguish the influence of penguins from that of other animals. In our previous study, seal hairs were observed below $32 \mathrm{~cm}$ of the sediment profile (corresponding to ca. $1490 \mathrm{AD}$ ), and abruptly increased below $35 \mathrm{~cm}^{17}$. We interpret this finding as indicating that the sampling site was primarily a seal haulout and molting location during Period I. Total vegetation abundance, as indicated by phytols, remained at low levels throughout this period. From ca. $1490 \mathrm{AD}$ onward, the concentrations of cholesterol + cholestanol increased quickly, and total vegetation abundance displayed a similar trend. Contrarily, seal hairs disappeared from the sediment, suggesting that seals moved from this locale and penguins then began to occupy it. During Period II, penguin populations and total vegetation abundance remained at high levels. The abundance of the two species of plants also increased early in this period and algae stayed at a high level, while lichens abruptly decreased and disappeared. At ca. $1670 \mathrm{AD}$, the penguin population and vegetation abundance decreased and remained at low levels during Period III. Algae abundance decreased with the penguin population, but both temporarily recovered at ca. 1850-1890 AD. Contrarily, lichens rapidly recovered with the decline of the penguin population and stayed at relatively high levels throughout this period. From ca. 1950 AD, penguin populations continuously grew, which was supported by the observation in Cape Royds from 1959 to $1995^{18}$.

Evolution of the penguin colonies: animals and plants. In Antarctica, with its limited terrestrial biodiversity, penguin (or seal) colonies and associated plants represent a simple ecosystem. The droppings of penguins and seals contribute to the formation of soil and provide nutrients for vegetation. Around these colonies, algae, mosses and lichens grow in the enriched soils. Mosses did not occur around our sampling site; algae were the dominant plants compared to a limited number of lichens growing on the surface of stones. According to previous studies, algae need a large amount of nutrients input via penguin guano. Lichens need lower nutrient input but are endangered by the trampling of penguins $s^{1,2}$. Therefore, algae abundance is dependent on the presence of penguins, while lichens have a contrary trend (Figure $3 \mathrm{f}-\mathrm{g}$ ). As the total amount of vegetation is controlled by algae, the variation of the total vegetation abundance was similar to the trend of penguin (or seal) populations in the past 700 years. The correlation coefficient between cholesterol + cholestanol and phytol was calculated at 0.86 $\left(\mathrm{R}^{2}=0.74\right)$.

\section{Discussion}

The Ross Sea region experienced the LIA from ca. 1500 to $1800 \mathrm{AD}^{19}$, when the summer temperature was about $2^{\circ} \mathrm{C}$ colder than that during the past 200 years ${ }^{20}$. Organisms are apt to synthesize more unsaturated fatty acids at low temperatures ${ }^{21,22}$. Kawamura and Ishiwatari ${ }^{23}$ observed greater ratios of fatty acids $\mathrm{C}_{18: 2} / \mathrm{C}_{18: 0}$ during colder periods in a sediment core collected in Lake Biwa, Japan, a method also applied successfully in Antarctica ${ }^{24}$. For our samples, the $\mathrm{C}_{18: 2} / \mathrm{C}_{18: 0}$ ratios showed little variation aside from a few samples. However, during Period II which was optimum for penguins (shaded areas in Figure 4), $\mathrm{C}_{18: 0}$ was absent at the depths of 22.2 (1660 AD), 25.8 (1620 AD), 28.2 (1570 AD), and $29.4 \mathrm{~cm}$ (1550 AD), indicating cold conditions. Low temperatures during Period II are supported by ice core record of stable isotopes $(\delta \mathrm{D})$ at Taylor Dome $\left(77^{\circ} 47^{\prime} 47^{\prime \prime} \mathrm{S}\right.$, $158^{\circ} 43^{\prime} 26^{\prime \prime}$ E) where a trough during this period is evident ${ }^{25}$ (Figure 4g). Moreover, a core from the Mt. Erebus Saddle $\left(77^{\circ} 30.9^{\prime} \mathrm{S}, 167^{\circ} 40.59^{\prime} \mathrm{E}\right)$ also records a downtrend from ca. $1500 \mathrm{AD}^{19}$ (Figure 4f). In general, the southern Ross Sea region was abandoned by breeding Adélie penguins for 900 years until ca. $850 \mathrm{AD}^{11}$, though a radiocarbon date on eggshell from one abandoned site at the south colony of Cape Bird indicates an earlier appearance there, prior to our Period I at 690-960 AD (Emslie, unpublished.). Further, our data support those of Polito, et al. ${ }^{10}$ in that the north colony at Cape Bird was used only as a molting site by penguins until about $1250 \mathrm{AD}$.

For the northwest beach of Cape Bird, the history of Adélie penguin colonies was even shorter, from ca. 1490 AD. Then the population rapidly increased and remained at markedly higher levels

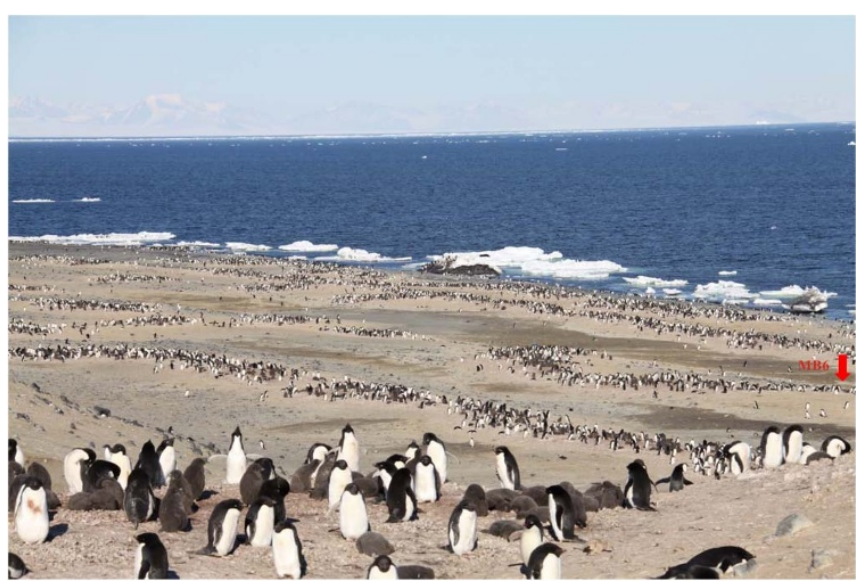

Figure $2 \mid$ Photo of the sampling site taken by X. D. Liu. 


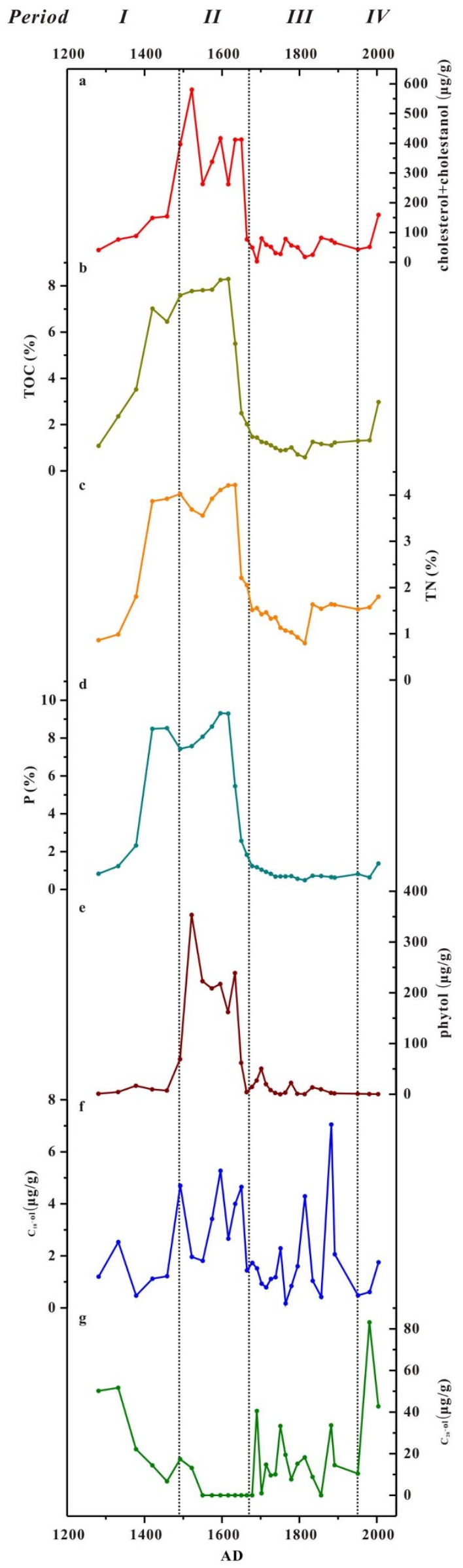

Figure 3 | Variation in penguin or seal populations with vegetation abundance from proxy indices in the sediment profile MB6 at Cape bird over the past 700 years. (a), population change; Cholesterol + cholestanol concentrations represented seal population during Period I and represented penguin population during Period $I I, I I I$ and $I V$. (b), (c) and (d), traditional inorganic indexes (TOC, TN and P) for penguins; the original data were reported by Nie, et al. ${ }^{17}$. (e), the change of total vegetation abundance indicated by phytol concentrations. (f), algae abundance change indicated by $\mathrm{C}_{18}$-ol concentrations. (g), lichen abundance change indicated by $\mathrm{C}_{28}$-ol concentrations.

during this cold interval than during later periods. Nevertheless, this trend is contrary to results from other regions much farther north. At Zolotov Island, East Antarctica $\left(68^{\circ} 39^{\prime} \mathrm{S}, 77^{\circ} 52^{\prime} \mathrm{E}\right)$, and Ardley Island, Antarctic Peninsula ( $62^{\circ} 13^{\prime} \mathrm{S}, 58^{\circ} 56^{\prime} \mathrm{W}$; Figure 1), Adélie penguin populations stayed at relatively low levels during our Period $I I^{3,6,8}$ (Figure $4 \mathrm{~b}-\mathrm{d}$ ). Furthermore, previous studies at low latitudes in the Antarctic have indicated that penguin populations, including Adélie, Gentoo (Pygoscelis papua) and Chinstrap penguins (Pygoscelis antarctica), increased when the climate became warmer and decreased when it became colder ${ }^{1-8}$.

Penguin population dynamics are affected by variations of climatic and environmental factors, such as sea surface temperature, air temperature, sea ice extent, snow cover, wind and the abundance of food ${ }^{4,8,18,26,27}$. Both extremely high and low temperature is seemingly unfavorable for the survival of pygoscelid penguins ${ }^{28}$. Temperature influences penguins mainly by driving change in these environmental conditions. Increasing temperature may result in increased snow-fall ${ }^{29}$. Thick snow cover prevents penguins from building nests early enough in the summer to complete the nesting cycle, thereby affecting the penguin population productivity and growth $^{29,30}$. During the LIA, the decreased snow accumulation in the Ross Sea region ${ }^{20}$ likely favored breeding penguins. More importantly, sea surface temperature as well as prevailing winds indirectly affect penguin populations by controlling sea ice extent and concentration $^{31}$. During cold periods, increased sea ice can prevent beach access by penguins to their colonies. Moreover, more northerly sea ice extent may make it difficult for penguins to reach the food-rich waters which are south of the southern boundary of the Antarctic Circumpolar Current ${ }^{32}$. The lack of food affects the survival of penguins, especially juveniles and subadults. In this manner climate affects the trends in penguin populations over $100 \mathrm{~s}$ to $1000 \mathrm{~s}$ of years. In the Ross Sea, Adélie penguin colonies have appeared and disappeared throughout this region over the past 8000 years in response to these environmental variables ${ }^{11}$. A warm period at 4000$2000 \mathrm{BP}$, the penguin 'optimum' ${ }^{14}$, saw an expansion in penguin colonies in the southern Ross Sea. The optimum in this study (Period IV) is a warm period with a reduction in sea ice extent ${ }^{18}$ that also favors penguin population expansion.

However, the influence of sea ice is critical. Algae under sea ice is an important food source for krill ${ }^{33}$, which in turn is an important prey for penguins. Thus, extended sea ice provides abundant krill and subsequently has a remarkable impact on the supply of food for penguins. Besides the increased sea ice extent, prevailing katabatic winds also increased in the Ross Sea during the LIA ${ }^{20}$. Strong winds caused sea-ice to split and created more polynya areas in the Ross $\mathrm{Sea}^{19}$. Larger size of polynya favors beach access by penguins to their colonies and increases the proportion of breeding penguins ${ }^{34}$. Furthermore, prevalent katabatic winds during the LIA were adverse to snow precipitation and resulted in decreased snow accumulation $^{20}$, which favored the breeding of penguins.

Beside climatic and environmental changes, emigrations also cause local variations in penguin populations. Penguins began to occur at our sampling site when seals abandoned it at ca. $1490 \mathrm{AD}$, the beginning of the LIA. Obviously, these penguins emigrated from other locations. This emigration might be associated with 


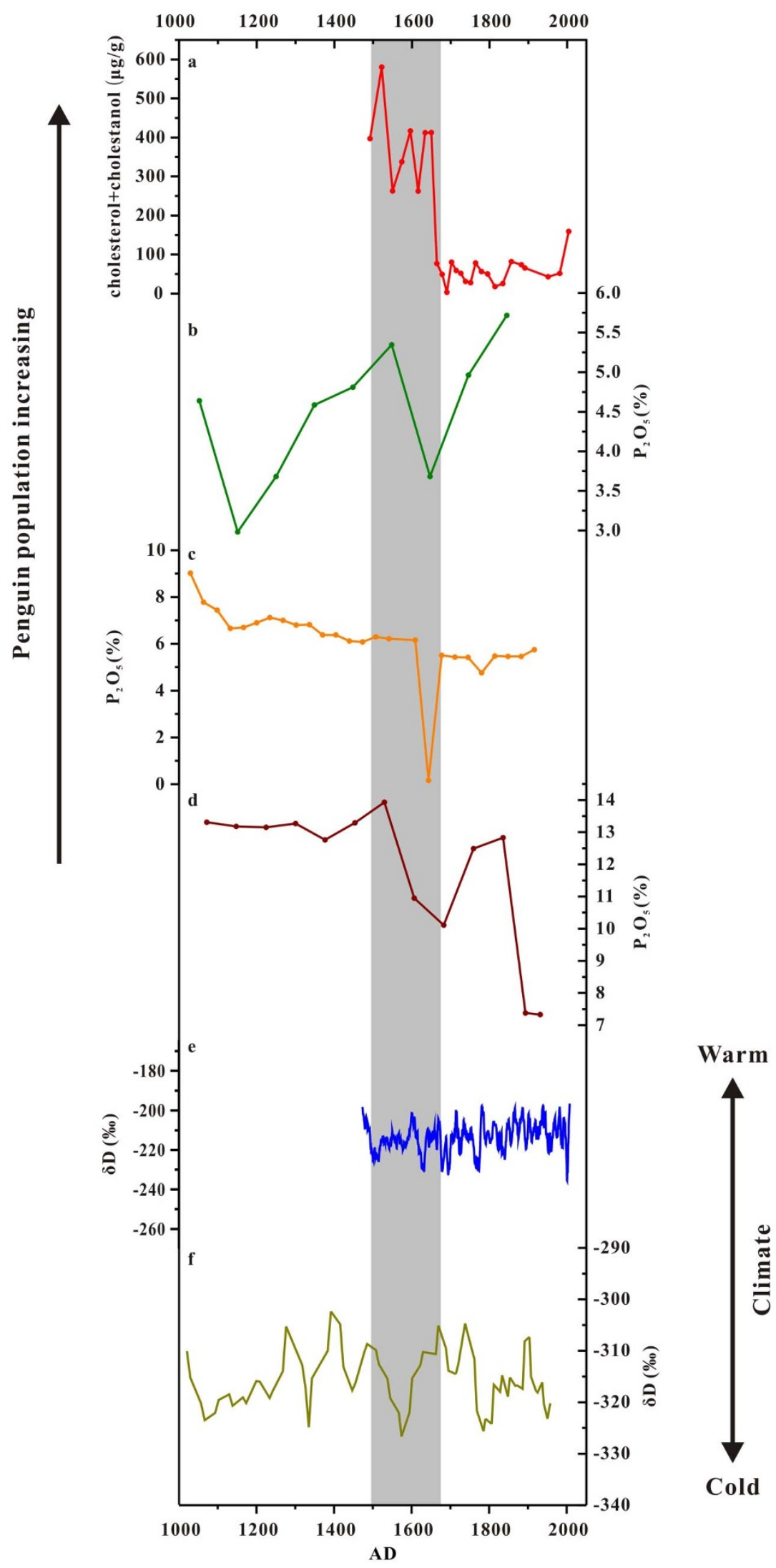

Figure $4 \mid$ Proxy indices of penguin populations and climate records. The shaded areas correspond to Period II, an optimum for penguins.

(a), penguin population changes from the sediment profile MB6 at Cape Bird as indicated by the sums of cholesterol and cholestanol concentrations. (b), penguin population changes from the sediment core ZOL4 ${ }^{8}$ at Zolotov Island as indicated by the P concentrations. (c) and (d), penguin population changes from the sediment cores $\mathrm{Y}^{3}$ and $\mathrm{Y}^{6}$ at Ardley Island as indicated by the $\mathrm{P}$ concentrations. (e), climate changes from the $\delta \mathrm{D}$ records in the Mt. Erebus Saddle ice core (100-points smoothed); the original data were reported by Rhodes, et al. ${ }^{19}$. (f), climate changes from the $\delta \mathrm{D}$ records in the Taylor Dome ice core (3-points smoothed); the original data were reported by Steig, et al. ${ }^{25}$. 


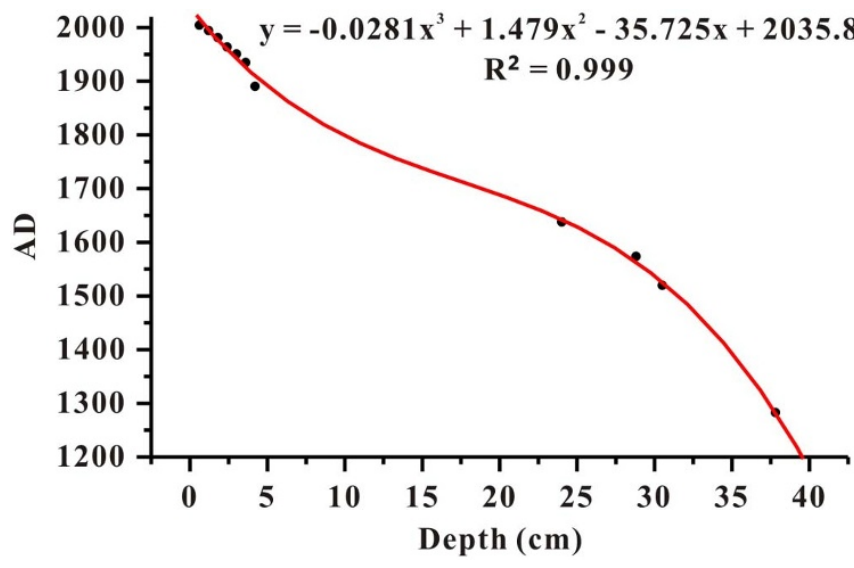

Figure $5 \mid$ Chronology of the sediment profile MB6. The ages were determined by ${ }^{210} \mathrm{~Pb}$ dates and ${ }^{14} \mathrm{C}$ dates, and the age-depth relationship was fitted with a cubic polynomial.

deteriorating environmental conditions in southern regions when the LIA began. The movement of penguins and thus alterative population distributions has been documented in the Ross Sea region ${ }^{35}$ and Terra Nova Bay region $\left(74^{\circ} 53^{\prime} \mathrm{S}, 163^{\circ} 45^{\prime} \mathrm{E}\right)^{36}$. This emigration of penguins to the sampling site may be accomplished in a short time and causes abruptly elevated populations. For instance, the movement of Adélie penguins to new breeding sites could occur over 1-2 decades in the Windmill Islands, East Antarctica ${ }^{37}$. This study suggests possibly different response to climate change by penguins at low latitudes and high latitudes in the Antarctic. The increased polynya accompanied by more convenient access to open water, abundant food for penguins, decreased snow-fall, as well as emigration from other sites might have been drivers for the increase in penguin populations during the LIA. Nonetheless, the $\mathrm{MB}_{6}$ sediment profile could record historical penguins in limited spatial range. More continuous records of penguins are needed for a better understanding of the population dynamics at high latitudes in the Antarctic.

\section{Methods}

Sampling. The sediment profile and core series MBs (McMurdo Sound and Cape Bird) were collected during an investigation in the Ross Sea region in January, 2010 ${ }^{17}$. The sediment profile for this study (MB6) was obtained from a catchment on the second terrace above sea level at Cape Bird on the north side of Ross Island (Figure 1 and 2). The MB6 profile was collected from a pit excavated at the sampling site. Breeding penguins spread from the sampling site to higher terraces at about $300 \mathrm{~m}$ above the sea level, covering an extent of more than $5 \mathrm{~km}$. The MB6 profile recorded the historical penguin populations in this spatial range. Seals were not discovered around the sampling site. The profile was directly sectioned in the field at $0.6 \mathrm{~cm}$ intervals and then stored in a freezer at $-20^{\circ} \mathrm{C}$ until analysis. The detailed procedures for sampling are described elsewhere ${ }^{17}$.

Chemical analysis. Thirty-two samples of the sectioned sediment profile were selected for organic analysis. Before analysis, sediment samples were freeze-dried and ground through a 140 mesh screen. Details of the analytical procedure for molecular markers was previously described ${ }^{1,2}$. Briefly, the dried sediment samples were Soxhlet extracted for $72 \mathrm{~h}$ with $180 \mathrm{~mL}$ mixed solvent (dichloromethane:methanol 2:1, V/ V). The extracts were concentrated by rotary evaporation and afterwards saponified using $0.5 \mathrm{M} \mathrm{KOH}$ dissolved in methanol. Then each of the saponified extracts was divided into three portions (hydrocarbons fraction, alcohols fraction and acids fraction) through controlling chemical conditions. Neutral lipids were partitioned out of each saponified extract with hexane. Acidic lipids were separated by adjusting PH to 2 with $0.5 \mathrm{M} \mathrm{HCl}$ and then extracted with mixed solvent (dichloromethane:hexane $1: 9, \mathrm{~V} / \mathrm{V})$. Neutral lipids were further divided on $5 \%$ deactivated silica gel column chromatography using different solvents of increasing polarity. Hydrocarbons were eluted with hexane and then alcohols, including n-alkanols and sterols, were eluted with ethyl acetate. The alcohols and acids fractions were silylanized with $\mathrm{N}, \mathrm{O}$-bis(trimethylsilyl)-trifluoroacetamide (BSTFA) to form trimethylsilyl (TMS)-ether derivatives, and then analyzed by a gas chromatography-mass selective detector.

Dating. The chronology of the sediment profile $\mathrm{MB} 6$ was determined by ${ }^{14} \mathrm{C}$ dating and ${ }^{210} \mathrm{~Pb}$ dating. The detailed method was described elsewhere ${ }^{5,38}$. The top $4.2 \mathrm{~cm}$ sediments were analyzed for ${ }^{210} \mathrm{~Pb}$ with Ortec HPGe GWL series detectors and showed a record of about 120 years. ${ }^{14} \mathrm{C}$ ages were determined by accelerator mass spectrometry(AMS) using the guano sediments as well as hairs and bones in the sediments. The ${ }^{14} \mathrm{C}$ ages were calibrated for the marine carbon reservoir effect using a $\Delta \mathrm{R}=750 \pm 50 \mathrm{yr}^{11}$ and the CALIB 4.3 software program with the INTCAL98 calibration dataset ${ }^{39}$. Combined with seven ${ }^{210} \mathrm{~Pb}$ dates and four ${ }^{14} \mathrm{C}$ dates, a polynomial curve ${ }^{5}$ was fitted to the age-depth relationship (Figure 5). The profile represents about 700 years of deposition.

1. Wang, J. J., Wang, Y. H., Wang, X. M. \& Sun, L. G. Penguins and vegetations on Ardley Island, Antarctica: evolution in the past 2,400 years. Polar Biol. 30, 1475-1481 (2007).

2. Huang, J., Sun, L., Huang, W., Wang, X. \& Wang, Y. The ecosystem evolution of penguin colonies in the past 8,500 years on Vestfold Hills, East Antarctica. Polar Biol. 33, 1399-1406 (2010).

3. Sun, L. G., Xie, Z. Q. \& Zhao, J. L. Palaeoecology - A 3,000-year record of penguin populations. Nature 407, 858-858 (2000).

4. Sun, L. \& Xie, Z. Relics: penguin population programs. Sci. Prog. 84, 31-44 (2001)

5. Liu, X. D. et al. A preliminary record of the historical seabird population in the Larsemann Hills, East Antarctica, from geochemical analyses of Mochou Lake sediments. Boreas 36, 182-197 (2007).

6. Liu, X., Sun, L., Xie, Z., Yin, X. \& Wang, Y. A 1300-year record of penguin populations at Ardley Island in the Antarctic, as deduced from the geochemical data in the ornithogenic lake sediments. Arct. Antarct. Alp. Res. 37, 490-498 (2005).

7. Huang, T., Sun, L. G., Wang, Y. H., Liu, X. D. \& Zhu, R. B. Penguin population dynamics for the past 8500 years at Gardner Island, Vestfold Hills. Antarct. Sci. 21, 571-578 (2009)

8. Huang, T., Sun, L., Wang, Y. \& Kong, D. Late Holocene Adélie penguin population dynamics at Zolotov Island, Vestfold Hills, Antarctica. J. Paleolimnol. 45, 273-285 (2011).

9. Emslie, S. D., Berkman, P. A., Ainley, D. G., Coats, L. \& Polito, M. Late-Holocene initiation of ice-free ecosystems in the southern Ross Sea, Antarctica. Mar. Ecol.Prog. Ser. 262, 19-25 (2003).

10. Polito, M., Emslie, S. D. \& Walker, W. A 1000-year record of Adélie penguin diets in the southern Ross Sea. Antarct. Sci. 14, 327-332 (2002).

11. Emslie, S. D., Coats, L. \& Licht, K. A 45,000 yr record of Adelie penguins and climate change in the Ross Sea, Antarctica. Geology 35, 61-64 (2007).

12. Taylor, R. \& Wilson, P. Recent increase and southern expansion of Adelie penguin populations in the Ross Sea, Antarctica, related to climatic warming. N. Z. J. Ecol. 14, 25-29 (1990).

13. Taylor, R., Wilson, P. \& Thomas, B. Status and trends of Adelie penguin populations in the Ross Sea region. Polar Rec. 26, 293-304 (1990).

14. Baroni, C. \& Orombelli, G. Abandoned Penguin Rookeries as Holocene Paleoclimatic Indicators in Antarctica. Geology 22, 23-26 (1994).

15. Cox, P. M., Betts, R. A., Jones, C. D., Spall, S. A. \& Totterdell, I. J. Acceleration of global warming due to carbon-cycle feedbacks in a coupled climate model. Nature 408, 184-187 (2000).

16. Root, T. L. et al. Fingerprints of global warming on wild animals and plants. Nature 421, 57-60 (2003).

17. Nie, Y., Liu, X., Sun, L. \& Emslie, S. D. Effect of penguin and seal excrement on mercury distribution in sediments from the Ross Sea region, East Antarctica. Sci. Total Environ. 433, 132-140 (2012).

18. Croxall, J., Trathan, P. \& Murphy, E. Environmental change and Antarctic seabird populations. Science 297, 1510-1514 (2002).

19. Rhodes, R. et al. Little Ice Age climate and oceanic conditions of the Ross Sea, Antarctica from a coastal ice core record. Clim. Past. 8, 215-262 (2012).

20. Bertler, N., Mayewski, P. \& Carter, L. Cold conditions in Antarctica during the Little Ice Age - Implications for abrupt climate change mechanisms. Earth Planet. Sci. Lett. 308, 41-51 (2011).

21. Marr, A. G. \& Ingraham, J. L. Effect of temperature on the composition of fatty acids in Escherichia coli. J. Bacteriol. 84, 1260-1267 (1962).

22. Kawamura, K., Ishiwatari, R. \& Yamazaki, M. Identification of polyunsaturated fatty acids in surface lacustrine sediments. Chem. Geol. 28, 31-39 (1980).

23. Kawamura, K. \& Ishiwatari, R. Polyunsaturated fatty acids in a lacustrine sediment as a possible indicator of paleoclimate. Geochim. Cosmochim. Ac. 45, 149-155 (1981)

24. Zhang, G., Sheng, G. Y., Peng, P. A. \& Zheng, H. H. Molecular organic geochemical peculiarities of lacustrine core sediments in Fildes Peninsula, King George Island, Antarctica. Chin. Sci. Bull. 45, 67-70 (2000).

25. Steig, E. J. et al. Wisconsinan and Holocene climate history from an ice core at Taylor Dome, western Ross Embayment, Antarctica. Geogr. Ann. Ser. A-Phys. Geogr. 82A, 213-235 (2000).

26. Fraser, W. R., Trivelpiece, W. Z., Ainley, D. G. \& Trivelpiece, S. G. Increases in Antarctic penguin populations: reduced competition with whales or a loss of sea ice due to environmental warming? Polar Biol. 11, 525-531 (1992).

27. Ainley, D. et al. Antarctic penguin response to habitat change as Earth's troposphere reaches $2^{\circ} \mathrm{C}$ above preindustrial levels. Ecol. Monogr. 80, 49-66 (2010).

28. Sun, L. \& Liu, X. Eco-environmental change records of Antarctic ice-free areas in the sediments influenced by marine animals. Adv. Clim. Change Res. 3, 35-40 (2007). 
29. Patterson, D. L., Easter-Pilcher, A. \& Fraser, W. R. The effects of human activity and environmental variability on long-term changes in Adélie penguin populations at Palmer Station, Antarctica, Montana State University, Bozeman, (2003).

30. Bricher, P., Lucieer, A. \& Woehler, E. J. Population trends of Adélie penguin (Pygoscelis adeliae) breeding colonies: a spatial analysis of the effects of snow accumulation and human activities. Polar Biol. 31, 1397-1407 (2008).

31. Jenouvrier, S., Barbraud, C. \& Weimerskirch, H. Sea ice affects the population dynamics of Adélie penguins in Terre Adélie. Polar Biol. 29, 413-423 (2006).

32. Wilson, P. et al. Adélie penguin population change in the pacific sector of Antarctica: relation to sea-ice extent and the Antarctic Circumpolar Current. Mar. Ecol.-Prog. Ser. 213, 301-309 (2001).

33. Brierley, A. S. et al. Antarctic krill under sea ice: elevated abundance in a narrow band just south of ice edge. Science 295, 1890-1892 (2002).

34. Ainley, D. G. et al. Decadal-scale changes in the climate and biota of the Pacific sector of the Southern Ocean, 1950s to the 1990s. Antarct. Sci. 17, 171-182 (2005).

35. LaRue, M. A. et al. Climate Change Winners: Receding Ice Fields Facilitate Colony Expansion and Altered Dynamics in an Adélie Penguin Metapopulation. Plos One 8, e60568 (2013).

36. Shepherd, L. et al. Microevolution and mega-icebergs in the Antarctic. Proc. Natl. Acad. Sci. USA 102, 16717-16722 (2005).

37. Emslie, S. D. \& Woehler, E. J. A 9000-year record of Adelie penguin occupation and diet in the Windmill Islands, East Antarctica. Antarct. Sci. 17, 57-66 (2005).

38. Huang, T., Sun, L. G., Wang, Y. H. \& Zhu, R. B. Penguin occupation in the Vestfold Hills. Antarct. Sci. 21, 131-134 (2009).

39. Liu, X. et al. Paleoenvironmental implications of the guano phosphatic cementation on Dongdao Island in the South China Sea. Mar. Geol. 247, 1-16 (2008).

\section{Acknowledgements}

This research was supported by grants from the National Natural Science Foundation of China (Project Nos. 40231002, 41025020), the Chinese Arctic and Antarctic Administration (Projects Nos. CHINARE2013-04-01, CHINARE2013-04-04), the Fundamental Research Funds for the Central Universities. Field work at Cape Bird was supported by a National Science Foundation grant (ANT 0739575) to S. Emslie with logistical support from Raytheon Polar Services. We thank David G. Ainley for his helpful comments on this manuscript. The authors acknowledge the State Key Laboratory of Organic Geochemistry, Guangzhou Institute of Geochemistry, Chinese Academy of Science (CAS) for all analysis performed there.

\section{Author contributions}

Q.H.H., Z.Q.X. and L.G.S. contributed equally to the design of the study and preparation of the manuscript. S.D.E. contributed to the discussion of results and manuscript refinement. X.D.L. and S.D.E. contributed to the sample collection. Q.H.H., Z.Q.X. and L.G.S. contributed to analysis.

\section{Additional information}

Supplementary information accompanies this paper at http://www.nature.com/ scientificreports

Competing financial interests: The authors declare no competing financial interests.

How to cite this article: Hu, Q.-H., Sun, L.-G., Xie, Z.-Q., Emslie, S.D. \& Liu, X.-D. Increas in penguin populations during the Little Ice Age in the Ross Sea, Antarctica. Sci. Rep. 3 2472; DOI:10.1038/srep02472 (2013). 